\title{
PSICHIKOS IR ELGESIO SUTRIKIMU VARTOJANT ALKOHOLI RYŠYS SU MĖGINIMU ŽUDYTIS AR TOKIO POELGIO GRE்SME BEI AMBULATORINIŲ PSICHIKOS SVEIKATOS PRIEŽIŪROS PASLAUGŲ NAUDOJIMUSI
}

\author{
Rūta Strockytè ${ }^{1}$, Eglè Šepetauskienè2, Virginija Adomaitien $\dot{e}^{1}$ \\ ${ }^{1}$ Lietuvos sveikatos mokslu universiteto Psichiatrijos klinika, \\ ${ }^{2}$ Lietuvos sveikatos mokslu universiteto Informaciniu technologiju centras
}

Raktažodžiai: psichikos ir elgesio sutrikimai vartojant alkoholį, skubi psichiatrinè pagalba, mėginimas žudytis ar tokio poelgio grèsmè, psichikos sveikatos priežiūros paslaugų naudojimasis.

\begin{abstract}
Santrauka
Alkoholio vartojimas - opi visuomenès sveikatos, ekonominè ir socialinė problema. Šiame straipsnyje siekiama atskleisti psichikos ir elgesio sutrikimų vartojant alkoholi ryšį su méginimu žudytis ar tokio poelgio grèsme bei ambulatorinių psichikos sveikatos priežiūros paslaugų naudojimusi. Analizuota medicininè dokumentacija pacientų, kurie kreipèsi ị Lietuvos sveikatos mokslų universiteto ligoninès Kauno klinikų (LSMUL Kauno klinikos) skubios pagalbos skyriu (SPS) ir buvo konsultuoti gydytojo psichiatro. Rezultatai. Nustatyta, kad psichikos ir elgesio sutrikimai vartojant alkoholị diagnozuoti kas septintam gydytojo psichiatro skubios pagalbos skyriuje konsultuotam pacientui, reikšmingai dažniau vyrams ir amžiumi reikšmingai jaunesniems nei moterys. Kas antram tiriamajam, kuriam diagnozuoti psichikos ir elgesio sutrikimai vartojant alkoholi, buvo reikalinga skubi psichiatro pagalba dèl mėginimo žudytis ar tokio poelgio grèsmès: vyrams reikšmingai dažniau nei moterims dèl mèginimo žudytis ar tokio poelgio grèsmès bei ūmios psichozès. Tiriamujų amžiaus vidurkis buvo 39,91 metai, ir vyrai amžiumi buvo reikšmingai jaunesni nei moterys. Daugiau nei pusė visų tiriamujų gyvenimo eigoje naudojosi ambulatorinėmis psichikos sveikatos priežiūros paslaugomis ir buvo konsultuoti gydytojo psichiatro bei vartojo psichotropinius vaistus nepriklausomai nuo lyties.
\end{abstract}

\section{Ivadas}

Pasaulio sveikatos organizacijos (PSO) duomenimis, dèl alkoholio poveikio visame pasaulyje kasmet netenkama 3,3 mln. žmonių gyvybių [1]. Lietuvos statistikos departamento duomenimis, 2016 metais kiekvienam 15 metų amžiaus ir vyresniam gyventojui teko 13,2 litru gryno alkoholio [2], tačiau realus suvartojimas gali būti didesnis, nes, PSO skaičiavimais, neapskaitytas alkoholis pasaulyje sudaro beveik ketvirtadali viso suvartojamo alkoholio [1].

Nustatyta, kad su alkoholio vartojimu siejamas sergamumas ir ligotumas tarp Lietuvos gyventojų 2010-2016 metais didèjo (2016 m., palyginus su 2010 m., naujai susirgusių asmenų buvo 5,8 karto daugiau). Didžiausias sergamumas buvo psichikos ir elgesio sutrikimais vartojant alkoholi [3]. $\mathrm{Su}$ alkoholio vartojimu susijusių ligų grupei priklauso ir išorinès mirties priežastys, tokios kaip nelaimingi atsitikimai keliuose, paskendimai, savižudybės ir kt. Vyrų mirčių dèl išorinių priežasčių, kurios siejamos su alkoholio vartojimu, užregistruota tris kartus daugiau nei moterų. Tarp išorinių mirties priežasčių, sietinų su alkoholio vartojimu, dominuoja tyčiniai susižalojimai: dèl savižudybių vartojant alkoholị per 2016 metus mirè 653 asmenys [3]. Literatūros duomenimis, 87,3 proc. nusižudžiusių asmenų nustatyti psichikos ir elgesio sutrikimai, tarp kurių dažniausiai nustatyti nuotaikos (afektiniai) sutrikimai bei psichikos ir elgesio sutrikimai vartojant alkoholi [4].

M. Hufordas galimą alkoholio vartojimo ir savižudybės rizikos santykị apibūdino dviem aspektais: priklausomybė nuo alkoholio, ją lydinti komorbidinè psichopatologija ir neigiami gyvenimo îvykiai veikia kaip distaliniai savižudybės rizikos faktoriai, o ūmus apsinuodijimas alkoholiu, kaip proksimalinis rizikos veiksnys, transformuoja savižudybès potencialą ị veiksmą [5]. 
SPS dažnai yra pirmoji vieta, kurioje suteikiamos psichikos sveikatos priežiūros paslaugos ir skubi medicinos pagalba mėginusiems nusižudyti ar patyrusiems tokio poelgio grèsmę [6]. Šiame tyrime analizavome LSMUL Kauno klinikų SPS gydytojo psichiatro konsultuotų pacientų medicininę dokumentaciją tikslu nustatyti bei ịvertinti diagnozuotu psichikos ir elgesio sutrikimų vartojant alkoholị ryšį su mèginimu žudytis ar tokio poelgio grèsme bei su ambulatoriniu psichikos sveikatos priežiūros paslaugų naudojimusi.

Darbo tikslas: nustatyti ir iqvertinti skubios pagalbos skyriuje gydytojo psichiatro diagnozuotu psichikos ir elgesio sutrikimų vartojant alkoholị ryši su mėginimu žudytis ar tokio poelgio grèsme bei ambulatorinių psichikos sveikatos priežiūros paslaugų naudojimusi.

\section{Tyrimo metodika}

Atlikta retrospektyvinè gydytojo psichiatro SPS konsultuotų pacientų, kuriems buvo nustatytas méginimas žudytis ar tokio poelgio grèsmé, medicininès dokumentacijos analizè. Tiriamają grupę sudarè $\geq 18$ metu amžiaus tiriamieji, kurie kreipèsi ị LSMUL Kauno klinikų SPS 2016.01.01 - 2016.12.31 dienomis. Atrinkti pacientai, kuriems pagal TLK-10-AM klasifikaciją buvo diagnozuoti psichikos ir elgesio sutrikimai vartojant alkoholi. Tyrimo rezultatai apdoroti naudojant aprašomosios statistinès analizès metodus, taikant statistinès duomenų analizès programą SPSS 20.0. bei EXCEL programą. Ryšys tarp požymių reikšmių laikytas statistiškai reikšmingu, kai apskaičiuotoji p reikšmė buvo mažesnè už pasirinktajị reikšmingumo lygmeni $\alpha=0,05$. Rezultatai pateikiami diagramose ir lentelèse.

\section{Tyrimo rezultatai}

Nustatyta, kad per minètą laikotarpi LSMUL Kauno klinikų SPS gydytojas psichiatras budinčio gydytojo nukreipimu konsultavo 3161 pacientą. Nustatyta, kad 15 proc. (471/3161) visu gydytojo psichiatro SPS konsultuotu pacientų sudare sergantys psichikos ir elgesio sutrikimais vartojant alkoholi. Taigi, galima teigti, jog kas 7-am gydytojo psichiatro konsultuotam pacientui diagnozuoti psichikos ir elgesio sutrikimai vartojant alkoholi (1 lentelè).

Nustatyta, kad vyrų, kuriems diagnozuoti psichikos ir elgesio sutrikimai vartojant alkoholị, buvo 69,6 proc. (328/471). Taigi, galime daryti išvadą, kad vyrams psichikos ir elgesio sutrikimai vartojant alkoholị diagnozuoti reikšmingai dažniau nei moterims (2 lentelè).

Nustatyta, kad bendras visų tiriamujų, kuriems diagnozuoti psichikos ir elgesio sutrikimai vartojant alkoholi, amžiaus vidurkis 41,37 metai. Vyrų amžiaus vidurkis - 40,5 metų, jų amžius svyravo nuo 18 iki 78 metų, moterų amžiaus vidurkis - 43,26 metai, jų amžius svyravo nuo 18 iki 86 metų.
Taigi, galime daryti išvadą, kad vyrai, kuriems diagnozuoti psichikos ir elgesio sutrikimai vartojant alkoholį, buvo reikšmingai jaunesni (3 lentelè).

Nustatyta, kad daugiau nei pusei visų tiriamujų $(59,45$ proc.; 280/471), kuriems buvo diagnozuoti psichikos ir elgesio sutrikimai vartojant alkoholi, buvo reikalinga skubi psichiatrine pagalba: 58,93 proc. (165/280) dèl mėginimo žudytis ar tokio poelgio grèsmès, 20,0 proc. $(56 / 280)$ dèl sunkios abstinencijos, 13,22 proc. (37/280) dèl ūmios psichozès, 7,85 proc. $(22 / 280)$ dèl ryškaus psichomotorinio sujaudinimo. Galime teigti, kad beveik kas antram tiriamajam, kuriam diagnozuoti psichikos ir elgesio sutrikimai vartojant alkoholi, buvo reikalinga skubi psichiatro pagalba dèl mèginimo žudytis ar tokio poelgio grèsmès (4 lentelè).

1 lentelè. Tiriamujų pasiskirstymas pagal diagnostines grupes (TLK-10-AM).

\begin{tabular}{|l|c|c|}
\hline Diagnostinė grupė & n & Proc. \\
\hline F00 organiniai psichikos sutrikimai & 1492 & 47,2 \\
\hline F10 psichikos sutrikimai vartojant alkoholi & $\mathbf{4 7 1}$ & $\mathbf{1 4 , 9}$ \\
\hline F20 kliedesiniai sutrikimai & 311 & 9,8 \\
\hline F30 afektiniai sutrikimai & 186 & 5,9 \\
\hline F40 neuroziniai sutrikimai & 406 & 12,8 \\
\hline F50 elgesio sindromai & 33 & 1,0 \\
\hline F60 asmenybės sutrikimai & 26 & 0,8 \\
\hline F70 protinis atsilikimas & 38 & 1,2 \\
\hline F80 psichologinės raidos sutrikimai & 2 & 0,1 \\
\hline F90 emocijų sutrikimai & 12 & 0,4 \\
\hline Nepatikslinti sutrikimai & 184 & 5,8 \\
\hline Iš viso & 3161 & 100 \\
\hline
\end{tabular}

2 lentelẻ. Diagnozuotų psichikos ir elgesio sutrikimų vartojant alkoholị ryšys su tiriamujjų lytimi.

\begin{tabular}{|l|c|c|c|}
\hline Tiriamieji pagal lyti & n & Proc. & p \\
\hline Vyrai & 328 & 69,6 & \multirow{2}{*}{$<0,001$} \\
\cline { 1 - 2 } Moterys & 143 & 30,4 & \\
\cline { 1 - 2 } Iš viso & 471 & 100 & \\
\hline
\end{tabular}

3 lentelė. Diagnozuotų psichikos ir elgesio sutrikimų vartojant alkoholį ryšys su tiriamujų amžiumi.

\begin{tabular}{|c|c|c|c|c|}
\hline Tiriamieji & $\begin{array}{l}\text { Amžiaus } \\
\text { vidurkis } \\
\text { (metais) }\end{array}$ & SD & Min - Max & p \\
\hline Vyrai & 40,54 & 12,69 & $18-78$ & \multirow[t]{3}{*}{0,035} \\
\hline Moterys & 43,26 & 13,20 & $18-86$ & \\
\hline Iš viso & 41,37 & 12,89 & $18-86$ & \\
\hline
\end{tabular}


Taip pat nustatyta, kad vyrams, kuriems diagnozuoti psichikos ir elgesio sutrikimai vartojant alkoholį, reikšmingai dažniau nei moterims buvo nustatytas skubios pagalbos poreikis dèl méginimo žudytis ar išsakomos tokio poelgio grèsmès $(61,0$ proc. vs 39,0 proc.) bei ūmios psichozès $(87,0$ proc. vs 13,0 proc., 5 lentelè)

Nustatyta, kad tiriamujų, kuriems diagnozuoti psichikos ir elgesio sutrikimai dèl alkoholio vartojimo ir skubi psichiatrinè pagalba dèl mėginimo žudytis ar tokio poelgio grèsmès, amžiaus vidurkis 39,91 metai, o vyrai amžiumi reikšmingai jaunesni nei moterys (32,28 m. vs 42,42 m., 6 lentelè).

Nustatyta, kad daugiau nei pusè visų tiriamujų, kuriems SPS diagnozuoti psichikos ir elgesio sutrikimai vartojant alkoholi, gyvenimo eigoje naudojosi ambulatorinemis psichikos sveikatos priežiūros paslaugomis ir buvo konsultuoti gydytojo psichiatro ( 55,0 proc. vs 45,0 proc.), iš jų 67,57 proc. buvo vyrai.

4 lentelè. Skubios psichiatrinès pagalbos poreikis dèl psichikos ir elgesio sutrikimų vartojant alkoholi.

\begin{tabular}{|l|l|l|}
\hline Būtinosios psichiatrinės pagalbos indikacijos & n & Proc. \\
\hline Mėginimas nusižudyti ar tokio poelgio grėsmè & 165 & 58,93 \\
\hline Sunki abstinencijos būklė & 56 & 20,0 \\
\hline Ūmi psichozė & 37 & 13,22 \\
\hline Ryškus psichomotorinis sujaudinimas & 22 & 7,85 \\
\hline Iš viso & 280 & 100 \\
\hline
\end{tabular}

5 lentelè. Skubios psichiatrinès pagalbos poreikio dèl psichikos ir elgesio sutrikimų vartojant alkoholị ryšys su tiriamujų lytimi. ${ }^{*} p=0,002 ; * * p=0,02$;

\begin{tabular}{|l|c|c|c|}
\hline $\begin{array}{l}\text { Būtinosios psichiatrinės } \\
\text { pagalbos indikacijos }\end{array}$ & $\begin{array}{c}\text { Vyrai } \\
\text { n (proc.) }\end{array}$ & $\begin{array}{l}\text { Moterys } \\
\text { n (proc.) }\end{array}$ & Iš viso \\
\hline $\begin{array}{l}\text { Mėginimas nusižudyti ar } \\
\text { tokio poelgio grėsmė }\end{array}$ & $\begin{array}{c}100^{*} \\
(61,0)\end{array}$ & $65(39,0)$ & $165(100,0)$ \\
\hline Ūmios psichozės & $\begin{array}{c}32^{* *} \\
(87,0)\end{array}$ & $5(22,7)$ & $37(100,0)$ \\
\hline $\begin{array}{l}\text { Ryškus psichomotorinis } \\
\text { sujaudinimas }\end{array}$ & $17(77,3)$ & $5(22,7)$ & $22(100,0)$ \\
\hline Sunki abstinencijos būklė & $43(77,0)$ & $13(23,0)$ & $56(100,0)$ \\
\hline Iš viso & 192 & 88 & 280 \\
\hline
\end{tabular}

6 lentelè. Mèginimo žudytis ar tokio poelgio grèsmès, sergant psichikos ir elgesio sutrikimais vartojant alkoholị, ryšys su amžiumi ir tiriamuju lytimi.

\begin{tabular}{|l|c|c|c|c|c|}
\hline Tiriamieji & $\mathbf{n}$ & $\begin{array}{c}\text { Amžiaus } \\
\text { vidurkis } \\
\text { (metais) }\end{array}$ & SD & Min - Max & p \\
\cline { 1 - 5 } Vyrai & 100 & $32,28^{*}$ & 10,41 & $19-64$ & \multirow{2}{*}{0,019} \\
\cline { 1 - 4 } Moterys & 65 & 42,42 & 11,85 & $18-74$ & \\
\cline { 1 - 5 } Iš viso & 165 & 39,91 & 11,14 & $18-74$ & \\
\hline
\end{tabular}

Nustatėme, kad daugiau nei pusė visų tiriamujų, kuriems SPS diagnozuoti psichikos ir elgesio sutrikimai vartojant alkoholi, gyvenimo eigoje vartojo psichotropinius vaistus (54,78 vs 45,22 proc.), iš jų 65,89 proc. buvo vyrai.

\section{Išvados}

1. Psichikos ir elgesio sutrikimai vartojant alkoholi diagnozuoti kas septintam gydytojo psichiatro skubios pagalbos skyriuje konsultuotam pacientui, reikšmingai dažniau vyrams ir amžiumi reikšmingai jaunesniems nei moterys.

2. Kas antram tiriamajam, kuriam diagnozuoti psichikos ir elgesio sutrikimai vartojant alkoholi, buvo reikalinga skubi psichiatrinè pagalba dèl mèginimo žudytis ar tokio poelgio grèsmès: vyrams reikšmingai dažniau nei moterims dèl mèginimo žudytis ar tokio poelgio grèsmès bei ūmios psichozès.

3. Tiriamujų, kuriems diagnozuoti psichikos ir elgesio sutrikimai dèl alkoholio vartojimo ir kuriems buvo reikalinga skubi psichiatrinè pagalba dèl mėginimo žudytis ar tokio poelgio grèsmès, amžiaus vidurkis buvo 39,91 metai, ir vyrai amžiumi buvo reikšmingai jaunesni nei moterys.

4. Daugiau nei pusė visų tiriamųjų, kuriems skubios pagalbos skyriuje diagnozuoti psichikos ir elgesio sutrikimai vartojant alkoholi, gyvenimo eigoje naudojosi ambulatorinèmis psichikos sveikatos priežiūros paslaugomis ir buvo konsultuoti gydytojo psichiatro bei vartojo psichotropinius vaistus nepriklausomai nuo lyties.

\section{Literatūra}

1. Global status report on alcohol and health. World Health Organization, 2014. http://www.who.int/substance_abuse/ publications/global_alcohol_report/msb_gsr_2014_1.pdf [2018-10-14].

2. Narkotikų, tabako ir alkoholio kontrolès departamentas. Alkoholio vartojimas ir padariniai. http://ntakd.lrv.lt/lt/statistikair-tyrimai/alkoholio-vartojimas-ir-padariniai [2018-10-05].

3. Alkoholio vartojimo padariniai Lietuvos gyventojų sveikatai. Higienos institutas, 2017. http://www.hi.lt/uploads/pdf/leidiniai/Informaciniai/Alkoholio\%20vartojimas.pdf [2018-10-08].

4. Arsenault-Lapierre G, Kim C, and Turecki G. Psychiatric diagnoses in 3275 suicides: a metaanalysis. BMC Psychiatry 2004; 4: 37.

https://doi.org/10.1186/1471-244X-4-37

5. Hufford MR. Alcohol and suicidal behavior. Clin Psychol Rev 2001; 21(5):797-811. https://doi.org/10.1016/S0272-7358(00)00070-2

6. Betz M, Arias S, Miller M, Barber C, Espinola J, Sullivan A. Change in emergency department providers' beliefs and practices after new protocols for suicidal patients. Psychiatr Serv 2015; 66(6): 625-631.

https://doi.org/10.1176/appi.ps.201400244 
THE CONNECTION BETWEEN MENTAL AND BEHAVIORAL DISORDERS IN THE USE OF ALCOHOL AND SUICIDE ATTEMPTS OR THE THREAT OF SUICIDE AND USAGE OF AMBULATORY MENTAL HEALTH CARE SERVICES

R.Strockytė, E.Šepetauskienė, V.Adomaitienè

Key words: mental and behavioral disorders in the use of alcohol, urgent psychiatric care, suicide attempts or the threat of suicide, usage of ambulatory mental health care services.

Summary

Alcohol consumption is an acute public health, economic and social problem. The purpose of this article is to determine and evaluate the relation between mental and behavioral disorders due to use of alcohol and attempting suicide also the use of outpatients mental health services. The data was collected by retrospective analysis of medical records. Analysis included 3161 patients after psychiatrist consultations. Results. Every seventh patient consul- ted by psychiatrist was diagnosed as mental and behavioral disorders due to use of alcohol; more frequently male who were significantly younger than female. Every second diagnosed with mental and behavioral disorders due to use of alcohol was evaluated as needed emergency psychiatrist care. The male more often needed for emergency psychiatrist care because of attempting suicide and acute psychosis. The mean age of all suicide attempters diagnosed as mental and behavioral disorders due to use of alcohol was 39,91 year and male were significantly younger than female. More than half of all suicide attempters diagnosed as mental and behavioral disorders due to use of alcohol had history of mental health care and using of psychotropic medications.

Correspondence to: strockyte@gmail.com

Gauta 2018-12-20

\section{KVIEČIAME PRENUMERUOTI “SVEIKATOS MOKSLŲ" ŽURNALĄ 2019 METAIS!}

Žurnalas "Sveikatos mokslai" (Index Copernicus, EBSCO host (Academic Search Complete), Gale (Academic OneFile), ProQuest (Ulrich's, Summon), Australia (ERA) 2012 Journal List (ERA ID 34962) skirtas visų specialybių gydytojams, slaugytojams ir kitiems specialistams, spausdina mokslinius straipsnius lietuvių, anglų kalbomis. Reikalavimai straipsniams atitinka mokslo leidiniams keliamus reikalavimus. Žurnalas kioskuose neparduodamas. Žurnalą, kuris leidžiamas kartą per du mėnesius, galima užsiprenumeruoti visuose Lietuvos pašto skyriuose, taip pat internetu: www.prenumeruok.lt Prenumeratos kaina nesikeičia: visiems metams - 36 EUR, šešiems mẻnesiams - 18 EUR, keturiems mẻnesiams - 12 EUR, dviem mėnesiams - 6 EUR. Prenumeratos kodas: 5348.

Žurnalo autoriams straipsnių spausdinimas mokamas. 